\title{
Incorporation Feasibility of Leather Residues in Bricks
}

\author{
J.B. Aguiar ${ }^{1}$, A. Valente ${ }^{2}$, M.J. Pires ${ }^{3}$ and T. Tavares ${ }^{4}$ \\ ${ }^{1}$ Civil Engineering Department, University of Minho, Guimarães, Portugal. \\ ${ }^{2}$ Institute of Development and Innovation Technologic of Minho, Braga, Portugal. \\ ${ }^{3}$ Institute of Development and Innovation Technologic of Minho, Braga, Portugal. \\ ${ }^{4}$ Biological Engineering Department, University of Minho, Braga, Portugal.
}

Keywords: residues, leather, bricks, toxicity, leaching, compressive strength, flexural strength.

\begin{abstract}
The footwear industry has strips of leather as one of its by-products. These leather residues, due to their high chromium content, can be regarded as a threat to the environment, particularly if no care is taken with their disposal. With the incorporation of the residues in ceramic products, after trituration, is possible to neutralise the eventual toxicity of chromium. In a laboratory study we produced prismatic bricks using clay from the region and incorporating 1,3 and 5\% (by mass) of leather residues. This corresponds at about 20,60 and $100 \%$ (by apparent volume). The moulds were filled up with paste and, in order to have some compactness, the ceramic paste was compressed with a spatula. After that, it began the process of drying and burning the bricks. They were tested to flexure, compression and leaching. The results showed that the toxicity of chromium disappeared in the bricks. The mechanical tests showed a decrease in strength for the specimens with leather residue. The compressive strength decreases about $22 \%$ for $1 \%$ of incorporation of leather residue. However, as bricks were lighter and more porous, we can expect that they are better for thermal isolation.
\end{abstract}

\section{Introduction}

The valorisation of by-products of all the industries is recommended to minimise their disposal and treatment. In the case of leather residues, their possible toxicity increases the problems. The introduction of these residues in the raw material of ceramic products was experimented during this study. To have a homogeneous mixture, a mechanical mixer was used. After that small bricks were made by filling up steel moulds. In order to have some compactness a spatula was used to applied pressure in the material. Industrially, we have other methods, like extrusion, which can give better results [1].

The drying and burning processes of the factory were simulated in the laboratory. Drying $[2,3]$ and burning [4] are very important phases for the production of ceramics. If dry and burn are not made correctly and slowly, the products can appear with cracks [5]. When the small bricks were completely burned the tests were started. Firstly, the bricks were tested to determine if they exhibit the characteristic of "Extraction Procedure Toxicity" [6]. Secondly, the possibility of bricks utilisation as construction material, in all the traditional applications [7], was analysed.

\section{Bricks Production}

For the bricks production was used clay from the region. The incorporations were 1,3 and $5 \%$ of leather residues by mass of clay. Some control specimens, without any incorporation, were made. In order to have the same plasticity, the quantity of water was different for each incorporation (Table 1). The mixture was made in a mechanical mixer, till had a homogeneous paste. After, steel moulds 
were filled up with a help of a spatula. To obtain better compactness some pressure was made with a spatula.

TABLE 1

Quantity of Water in the Pastes

\begin{tabular}{|c|c|}
\hline $\begin{array}{c}\text { Leather residues } \\
\text { incorporation [\%] }\end{array}$ & $\begin{array}{c}\text { Quantity of water } \\
{[\%]}\end{array}$ \\
\hline 0 & 26,0 \\
\hline 1 & 29,7 \\
3 & 30,2 \\
5 & 30,2 \\
\hline
\end{tabular}

The bricks had a prismatic form with the dimensions of $4 \times 4 \times 16 \mathrm{~cm}^{3}$. Four bricks for each incorporation were made. The bricks were removed from the moulds and the drying was made in five stages, in a drying stove, during 48 hours, with a temperature program from 30 to $100{ }^{\circ} \mathrm{C}$. The burn was made in a muffle where the highest temperature $\left(1000^{\circ} \mathrm{C}\right)$ was reached approximately in 12 hours and the bricks were maintained at this temperature for 1 hour. After burning, specially in the bricks with 3 and $5 \%$ of residues incorporation, some exterior pores were observed. They are a result of residues carbonisation.

\section{Leaching Tests}

Leaching tests were performed in accordance with [8]. The material was ground so that it passed trough a $9.5 \mathrm{~mm}$ sieve and then subjected to the extraction procedure. The samples obtained after filtration were analysed to determine total chromium $\left(\mathrm{Cr}_{\text {total }}\right)$ and hexavalent chromium $(\mathrm{Cr}(\mathrm{VI}))$. No significant concentrations were found (Table 2).

TABLE 2

Leaching Results for the Tested Bricks and Limit Values for Harmful Wastes [9]

\begin{tabular}{|c|c|c|}
\hline $\begin{array}{c}\text { Leather residues incorporation } \\
{[\%]}\end{array}$ & $\begin{array}{c}\mathrm{Cr} \text { total } \\
{\left[\mathrm{mgdm}^{-3}\right]}\end{array}$ & $\begin{array}{c}\mathrm{Cr}(\mathrm{VI}) \\
{\left[\mathrm{mgdm}^{-3}\right]}\end{array}$ \\
\hline 0 & $0,02-0,04$ & n.d. $^{*}$ \\
3 & $\leq 0,03$ & n.d. \\
5 & $\leq 0,04$ & $\leq 0,01$ \\
\hline Harmful waste & - & $0,1-0,5$ \\
\hline
\end{tabular}

(*) Not detected.

Since low concentrations were obtained in these samples, no tests were made with the $1 \%$ of incorporation bricks. These results show that chromium compounds are, basically, immobilised in the clay matrix. On the other hand, facing these results, the possibility of chromium losses during the burn came up. So, determinations of Total Chromium $\left(\mathrm{Cr}_{\text {total }}\right)$ in the brick material and in the leather residues were made (Tables 3 and 4).

TABLE 3

Total Chromium Concentrations for the Leather Residues and Brick Material ( 0 and 3\% of incorporation)

\begin{tabular}{|c|c|c|}
\hline $\begin{array}{c}\text { Leather residues } \\
\text { incorporation [\%] }\end{array}$ & $\begin{array}{c}\mathrm{Cr} \text { total } \\
{\left[\mathrm{mgdm}^{-3}\right]}\end{array}$ & $\begin{array}{c}\mathrm{Cr} \text { total } \\
{\left[\mathrm{gkg}^{-1}\right]}\end{array}$ \\
\hline 0 & 1 & 0,04 \\
3 & 19 & 0,76 \\
Leather residues & 1090 & 21,80 \\
\hline
\end{tabular}

Despite of the variation between the two analyses in the chromium concentrations of the control bricks ( $0 \%$ of incorporation) and leather residues, these results allow the rejection of the possibility 
of chromium volatilisation during the burn. The chromium concentration in the brick material was never inferior to the expected value regarding the concentrations in the raw materials.

TABLE 4

Total Chromium Concentrations for the Leather Residues and Brick Material ( 0 and $5 \%$ of incorporation)

\begin{tabular}{|c|c|c|}
\hline $\begin{array}{c}\text { Leather residues } \\
\text { incorporation [\%] }\end{array}$ & $\begin{array}{c}\mathrm{Cr} \text { total } \\
{\left[\mathrm{mgdm}^{-3}\right]}\end{array}$ & $\begin{array}{c}\mathrm{Cr} \text { total } \\
{\left[\mathrm{gkg}^{-1}\right]}\end{array}$ \\
\hline 0 & 5 & 0,2 \\
5 & 28 & 1,12 \\
Leather residues & 820 & 16,40 \\
\hline
\end{tabular}

\section{Mechanical Testing}

Flexure and compressive tests were made in accordance with [10]. The flexure test was a three point one. The compressive tests were made in the two halves of the original prism after failure by flexure. As the surfaces were plane and without any depressions no capping had to be done.

The results are presented in Figures 1 and 2. With 1\% of incorporation a decrease of $30 \%$ in the modulus of rupture and $22 \%$ in the compressive strength was found. The decrease of compressive strength is more significant for 3 and $5 \%$ of incorporation, around $45 \%$. For the modulus of rupture, after the minimum with $1 \%$ of incorporation, the values increase with the quantity of leather residues. show the variation of the modulus of rupture and of the compressive strength with the percentage of incorporation.

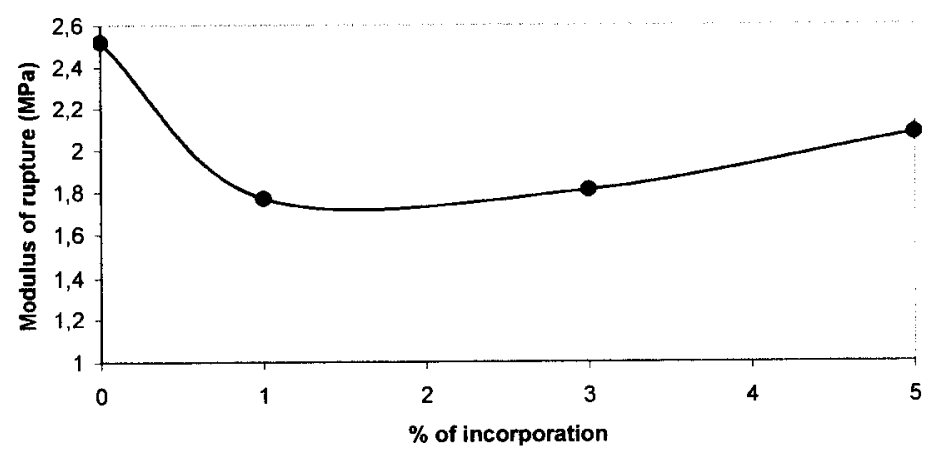

Fig. 1 - Variation of Modulus of Rupture with the \% of Leather Residues Incorporation. The observation of the interior of the specimens after the compressive tests shows that the quantity of pores (black areas), increase with the incorporation of residues. The black areas resulted from the carbonisation of residues.

\section{Conclusion}

The incorporation of leather residues in the raw material used to produce bricks is possible. Losses of chromium ( $\mathrm{Cr}$ (III) $+\mathrm{Cr}(\mathrm{VI})$ ) on leaching or volatilisation during the burn were not verified. However, there is some decrease in mechanical properties (modulus of rupture and compressive strength). So, it is necessary to limit the incorporation to around $1 \%$ by mass of clay. As the residues are very light, this represents a reasonable volume.

The incorporation decreases the volumetric mass of the bricks. This is due to the increase of porosity because the residues carbonise during the burn and most part of the place occupied by them results in holes. There is no problem on this because the alveolar bricks are good for thermal insulation and sound absorption [11]. So, with the incorporation of the leather residues there is some 
loss on mechanical strength but there is a winning in thermal and sound properties of the bricks. It is reasonable to think that these bricks can be used in partition walls.

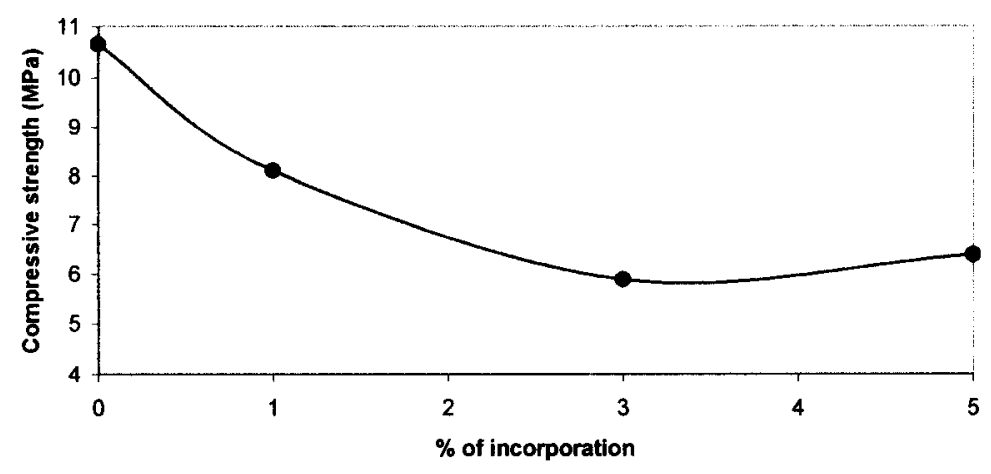

Fig. 2 - Variation of Compressive Strength with the \% of Leather Residues Incorporation.

\section{References}

[1] P. A. Janeway: Basics of extrusion, Ceramic Industry, Vol. 140, $\mathrm{N}^{\circ} 6$ (Business News Publishing, Ohio, 1993).

[2] A. Hall: Drying technology for today's manufacturer, Ceramic Industry, Vol. 142, $\mathrm{N}^{\circ} 5$ (Business News Publishing, Ohio, 1994).

[3] J. T. Jones: New emphasis on drying, Ceramic Industry, Vol. 142, No 4 (Business News Publishing, Ohio, 1994).

[4] J. T. Jones and M. F. Berard: Let's talk about combustion, Ceramic Industry, Vol. 140, No 6 (Business News Publishing, Ohio, 1993).

[5] J.W. Cotton: Ceramic processing to minimise flaws, Ceramic Industry, Vol. 140, No 6 (Business News Publishing, Ohio, 1993).

[6] EPA: Extraction Procedure Toxicity Test Method, Method 1310 (United States Environmental Protection Agency, USA, 1986).

[7] G. C. Robinson: Structural clay products, Engineered Materials Handbook, Vol. 4, Ceramics and Glasses (ASM International, Ohio, 1991).

[8] ASTM D 1687- 86: Standard test methods for chromium in water (American Society for Testing and Materials, Philadelphia, 1986).

[9] European Comission: Directive Proposal - residues disposal in controlled land field (European Comission, Brussels, 1991).

[10] ASTM C 67 - 93a: Standard test methods of sampling and testing brick and structural clay tile (American Society for Testing and Materials, Philadelphia, 1993).

[11] P. Principi, E. Ruffini and G. Zanarini: Thermal analysis to optimize the design of the alveolater bricks, Advances in Thermal Insulation, Eurotherm Seminar $\mathbf{n}^{\circ} 44$ (Espinho, Portugal 1995). 